\title{
Sistemas setoriais de inovação e infraestrutura de pesquisa no Brasil
}

Fernanda De Negri e Flávia de Holanda Schmidt Squeff (Org.)

Brasília: Ipea/Finep/CNPq, 2016

ISBN: 978-85-7811-268-4

\author{
Carlos Américo Pacheco*
}

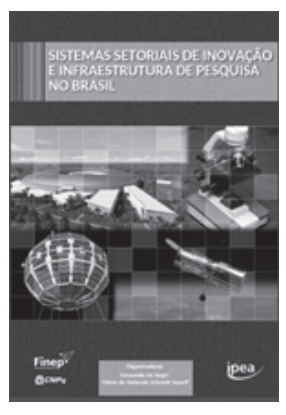

O livro Sistemas setoriais de inovação e infraestrutura de pesquisa no Brasil, lançado recentemente pelo Ipea, em parceria com a Finep e o $\mathrm{CNPq}$, traz uma radiografia ampla e detalhada da infraestrutura científica de nosso sistema nacional de inovação. Organizado por Fernanda De Negri e Flávia de Holanda Schmidt Squeff, a obra reúne uma coletânea de estudos que avaliam, sob diferentes ângulos, como está organizada a pesquisa no país, especialmente em termos dos equipamentos e instalações dos laboratórios de pesquisa de institutos e universidades.

Sua relevância maior talvez esteja em convalidar, com base em levantamento detalhado, que temos uma infraestrutura de pesquisa razoavelmente atualizada, mas essencialmente dispersa, resultado da natureza das ações de fomento das agências governamentais, que tendem a diluir suas ações, buscando atender a uma clientela crescente, com auxílios relativamente pequenos e dificuldades em direcionar recursos para infraestruturas compartilhadas, especialmente de grandes laboratórios multiusuários e abertos, como é comum na maioria dos países com sistemas de inovação mais consolidados.

Com base num mapeamento de cerca de dois mil laboratórios de pesquisa do país, realizado pelo Ipea, em parceria com o então MCTI, o CNPq e a Finep, englobando mais de cem unidades de pesquisa do MCTI, universidades e centros de 
pesquisa públicos e privados, esse projeto buscou aprofundar o diagnóstico sobre a efetividade dos fundos setoriais, notadamente do fundo de infraestrutura (CT-Infra), criado para viabilizar a modernização e ampliação da infraestrutura de pesquisa no país, mas que nunca foi adequadamente avaliado, além também de dar atenção a outras fontes de financiamento, inclusive do setor empresarial, a exemplo da Petrobras. ${ }^{1}$

Os 15 capítulos em que se divide o livro cobrem os aspectos centrais de avaliação desta infraestrutura de pesquisa e de algumas políticas relacionadas ao seu financiamento. De autoria das organizadoras da coletânea, o capítulo inicial apresenta a metodologia do trabalho e sintetiza seus principais resultados, que são retomados ao fim desta resenha.

Os capítulos seguintes (2 a 9) formam um mosaico acerca dos aspectos setoriais desta infraestrutura, enfocando o setor de defesa, saúde, aeronáutico, energias renováveis, tecnologias de informação e comunicação, petróleo, construção civil e agropecuário. Os capítulos finais (10 a 15) abordam aspectos gerais das políticas públicas ou recortes horizontais de análise, como a escala da infraestrutura e a produtividade da pesquisa, a relação entre esta infraestrutura e atividade de patenteamento, os serviços tecnológicos prestados pelos laboratórios, suas atividades de cooperação para a $\mathrm{P} \& \mathrm{D}$, as políticas de investimento em infraestrutura de pesquisa e as áreas científicas e instituições nas quais o Brasil se destaca ou é mais competitivo internacionalmente.

Elaborado por Flavia de Holanda Schmidt Squeff, o segundo capítulo discute o Sistema Setorial de Inovação em Defesa no Brasil, fazendo uma avaliação acerca da importância desta área para a pesquisa e inovação em alguns países e sobre a institucionalidade do caso brasileiro. A autora faz uma avaliação de 44 laboratórios ligados ao Ministério da Defesa. Com base nesta amostra, ela conclui pela relativa fragilidade da infraestrutura de pesquisa instalada na área de defesa, vis-à-vis os exemplos internacionais analisados, o que fica evidenciado pelo baixo número de pessoas dedicadas a estas atividades e pelo reduzido volume de recursos alocados para tal finalidade, quer em termos absolutos, quer em comparação com outros países. A conclusão é irrefutável, mas talvez sugira que, no futuro, procure-se ampliar a amostra, pois o número de pesquisadores relatado no levantamento difere muito do efetivo de pessoas alocadas nas principais unidades de pesquisa do Ministério da Defesa. Este problema não desqualifica a pesquisa, mas revela a necessidade de maior comprometimento das instituições com este tipo de pesquisa.

1 Este levantamento foi precedido de esforços iniciais, entre 2008 e 2009, de uma avaliação do Ipea da infraestrutura das unidades de pesquisa do então MCT, bem como de um estudo piloto realizado em 2012, também junto a estas unidades, para testar e validar o questionário que seria aplicado na pesquisa final. O trabalho foi resultado de uma intensa articulação entre MCT, CNPq e Ipea, para elaboração e teste do questionário, coleta e armazenamento das informaçôes, acompanhamento e suporte ao preenchimento do formulário e tratamento final e análise das informaçōes coletadas. 
O terceiro capítulo, de autoria de Thiago Caliari e Márcia Rapini, avalia a infraestrutura de pesquisa científica em saúde no Brasil, fazendo inicialmente uma comparação com a situação do Reino Unido e da Índia. O artigo traz uma breve descrição da evolução histórica desse sistema e seus principais atores: empresas, institutos de pesquisa e governo. Sua principal contribuição é a caracterização, em diversos aspectos, da infraestrutura de C\&T voltada para a saúde. Fica clara a complexidade desta estrutura e suas diferentes lógicas (privada e pública). No total são listadas 412 infraestruturas científicas, localizadas em 63 instituições, em que se destacam dois grandes laboratórios nacionais, ambos curiosamente fora da alçada do atual MCTIC. As conclusões reforçam o indicado em outros capítulos, de que esta infraestrutura científica ainda conta com escala pequena e há pouca conexão entre seus diversos atores, embora saliente-se que existe coerência entre as estratégias e os instrumentos de política pública, fato que talvez direcione para uma maior competitividade nacional nos próximos anos.

Dedicado ao setor aeronáutico, o quarto capítulo, produzido por Zil Miranda, inicia-se com uma descrição breve dos sistemas de P\&D aeronáutico e das correspondentes políticas dos Estados Unidos e Canadá, permitindo assim algum grau de comparação internacional. Em seguida, a autora faz uma breve caracterização das empresas que atuam no setor e das iniciativas governamentais de apoio, salientando a importância das compras governamentais e o papel relevante da Finep e do BNDES, mas também, em menor grau, da Fapesp e da Fapemig. Esta caracterização é complementada por um panorama das competências das principais instituiçóes de pesquisa e das universidades, bem como de suas cooperaçôes com o setor privado. $\mathrm{Na}$ sequência, com base no levantamento do Ipea-CNPq-Finep, a autora faz uma radiografia das 204 infraestruturas de pesquisa que atuam no setor aeronáutico. Em suas conclusões deixa evidente que, para enfrentar os desafios colocados (sustentabilidade, materiais, combustíveis, segurança e nova mobilidade), há ainda um longo caminho a percorrer para desenvolver uma infraestrutura de última geração e realizar $\mathrm{P} \& \mathrm{D}$ em áreas de alta complexidade.

No quinto capítulo, Gesmar Rosa dos Santos faz um mapeamento da infraestrutura laboratorial de pesquisa em energias renováveis no Brasil, sejam estas dedicadas (foco no setor), sejam circunstanciais. Afora temas avulsos, seis grandes fontes de energia são consideradas: biomassa; hidroeletricidade; solar; eólica; propagação das marés; e hidrogênio. A ideia é caracterizar este subsistema setorial de inovação: suas instituições, instrumentos e agentes. Parte-se de uma comparação com Estados Unidos e Alemanha, em que ficam claras certas diferenças: o fato de o Brasil ser 
iniciante ou um seguidor em termos tecnológicos; o baixo investimento privado em pesquisa nesta área; e o pequeno porte dos centros e institutos de pesquisa do Brasil, comparativamente aos outros países. A complexidade institucional é bem caracterizada: as funções de formulação, regulação e de coordenação; as funções de apoio à $\mathrm{P} \& \mathrm{D}$ e à inovação; as funções de execução da pesquisa; e, por fim, as funçôes de produção. Cerca de cem infraestruturas voltadas para esta questão são caracterizadas pelo uso dos dados levantados na pesquisa. Fica claro o perfil distinto do Brasil, em comparação com países líderes em pesquisa tecnológica, em termos tanto da fragilidade da coordenação quanto de ausência de políticas claras para o setor.

Enfocando o sistema de inovação no setor de tecnologias de informação e comunicação (TICs), o sexto capítulo, de autoria de João Maria de Oliveira, inicia-se com uma panorâmica do setor de TICs no mundo e das implicações da convergência tecnológica trazida pela digitalização, bem como pelas especificidades dos modelos de P\&D, inovação e de financiamento deste setor. A avaliação da situação brasileira salienta a importância histórica das políticas públicas, quer da reserva de mercado, quer do antigo Sistema Telebrás e do papel que seu Centro de P\&D desempenhava nesta arquitetura, quer também da Lei de Informática e do novo regime criado após a privatização das telecomunicações, em que as agências e bancos públicos convivem com novos órgãos reguladores e novos fundos. Apesar destas iniciativas, o autor evidencia a frustração destas políticas: seja em razão da forte dependência da importação de componentes; seja pelo baixo protagonismo tecnológico das empresas brasileiras. O estudo faz igualmente uma radiografia de 191 laboratórios atuantes no setor, de pequeno porte e muito dependentes de recursos públicos, com forte predomínio de pesquisa em aplicativos e menor grau de risco. Com base na amostra analisada, o autor avalia que se trata de infraestruturas tecnológicas com pouco foco, talvez em decorrência da pouca ligação com empresas, embora talvez fosse interessante investigar se o papel de alguns centros, como o $\mathrm{CPqD}$, não se dilui quando são enfocados laboratórios isolados e não o conjunto das instituições. Este resultado talvez exija no futuro uma investigação complementar, cruzando estes dados com os relatórios da Secretaria de Política de Informática (Sepin/MCTIC), para verificar se o conjunto dos centros que operam com recursos dos incentivos da Lei de Informática estão bem representados nesta amostra, assim como para mapear o movimento de transformação da natureza desta infraestrutura, a partir da estruturação de centros de $\mathrm{P} \& \mathrm{D}$ associados às grandes empresas do setor e investigar uma tese corrente, mas sem comprovação empírica, de que este marco regulatório não incentiva atividades de pesquisa mais ambiciosas e de longo prazo. 
O capítulo sete, de autoria de José Mauro de Morais e Lenita Turchi, analisa a infraestrutura de pesquisa no setor de petróleo e o papel fundamental da Petrobras no financiamento dessa infraestrutura de pesquisa. $\mathrm{O}$ texto faz uma avaliação inicial da evolução desse sistema e discute as mudanças ocorridas após a quebra do monopólio do petróleo, com o surgimento de novos atores: empresas petroleiras nacionais e estrangeiras; a Agência Nacional do Petróleo (ANP); o Fundo Setorial do Petróleo e Gás Natural (CT-Petro); e as universidades e centros de pesquisas voltados para atividades de P\&D. O estudo foca na análise da infraestrutura de laboratórios do setor, avaliando como as políticas de desenvolvimento tecnológico da Petrobras condicionaram este sistema, desde a criação de seu Centro de Pesquisas e Desenvolvimento (Cenpes), em 1963, até as diversas fases dos programas de capacitação tecnológica para águas profundas (Procap 1.000, 2000 e 3000), que retratam o aumento significativo da cooperação entre a Petrobras e as ICTs. O levantamento de campo permitiu fazer uma radiografia de 117 infraestruturas dedicadas ao setor. Por fim, o artigo faz uma análise comparativa com o caso Norueguês, mostrando algumas diferenças, como a não formação de um cluster de empresas nacionais e os distintos aparatos institucionais e de apoio ao setor industrial. Infelizmente não se pode cobrar dos autores abordar a situação atual do setor, duplamente afetada pela mudança no marco regulatório e pela triste situação da Petrobras, envolta no maior escândalo de corrupção do Brasil.

Jean Marlo Pepino de Paula aborda, no oitavo capítulo, a infraestrutura de pesquisa do setor da construção civil. O texto inicia-se com uma breve caracterização da indústria no país e das características da inovação em outros países, como Austrália, Nova Zelândia e Reino Unido. O autor sintetiza, também, o cenário brasileiro, mostrando a lenta evolução tecnológica do setor, além de relacionar as recentes iniciativas de inúmeros atores voltadas para inovações em edificações e obras de infraestrutura. Na sequência, com base nos dados coletados no levantamento de campo, é feita uma análise das características físicas e operacionais de 52 infraestruturas de pesquisa dedicadas ao setor. Algumas destas características - laboratórios multiusuários, financiamentos de grande porte de demandantes de serviços técnicos - sinalizam haver uma proximidade das empresas e de outras instituições com os laboratórios. Contudo, há uma predominância das atividades contínuas de pesquisa e ensino e de ensaios e testes, relativamente ao desenvolvimento de tecnologias.

O nono capítulo desta coletânea, elaborado por Bernardo Campolina, é o último com enfoque setorial e trata do sistema de inovação no setor agropecuário. $\mathrm{O}$ autor faz uma avaliação da situação da infraestrutura de pesquisa voltada para as 
ciências agrárias, com destaque para o papel da Embrapa. Em uma breve introdução, é situado o caso brasileiro em relação às experiências dos Estados Unidos, da Austrália e da Argentina. Em seguida, apresenta-se uma síntese da evolução histórica do sistema de pesquisa agrícola brasileiro, enfatizando primeiro a mudança de paradigma da revolução verde e da mecanização, e depois a nova mudança trazida com a biotecnologia. Como em qualquer síntese, especialmente de períodos tão longos, corre-se risco de passar muito rapidamente por alguns pontos, como é o caso da pesquisa do IAC sobre café e algodão, antes de 1930, ou da introdução da soja no cerrado e as pesquisas de Johanna Döberein, ou ainda das dificuldades financeiras mais recentes da Embrapa, que estão na raiz da redução de seu papel no mercado de sementes, ou mesmo das dificuldades derivadas da rigidez do marco regulatório de biossegurança. Mas o trabalho contribui bastante para entender a situação atual da infraestrutura de pesquisa em ciências agrárias, a partir da análise dos resultados do levantamento de campo, que permitem fazer uma radiografia de 284 destas infraestruturas. Isso possibilita entender seu elevado grau de maturação, mas também as melhorias que são necessárias para adequá-las aos padrões internacionais.

De autoria de Sérgio Kannebley Júnior e Renata de Lacerda Antunes Borges, o décimo capítulo busca identificar correlaçōes entre infraestrutura de pesquisa, com base no levantamento de campo, e a produtividade dos pesquisadores, medida pela sua publicação per capita (artigos em relação ao número de coautores), tentando descobrir qual configuração de laboratório estaria mais correlacionada com a produção científica. São cruzadas informaçōes de 1.756 laboratórios com dados dos currículos Lattes, sobre a produção científica de seus pesquisadores. A tipologia dos laboratórios foi definida por uma análise de cluster, com três tipos: intensivos em P\&D de tecnologias; laboratórios intensivos em pesquisa e ensino; e os simplesmente intensivos em pesquisa. Os resultados mostram que a produtividade per capita dos pesquisadores é positivamente correlacionada com o escopo de atividades e tamanho de cada laboratório, bem como com a participação de alunos de pós-graduação. Entre os três tipos de laboratórios, a principal conclusão é que a produtividade é maior naqueles intensivos em pesquisa e ensino, seguidos pelos intensivos em P\&D de tecnologias e, por fim, os intensivos em pesquisa. As conclusōes corroboram com a tese geral da publicação: "é possível concluir que tanto o escopo de atividades quanto o estoque de recursos físicos, que se determinam simultaneamente, também são determinantes da produtividade científica dos pesquisadores, sendo então responsáveis também por seus diferenciais de produtividade". São conclusões robustas, mas que talvez mereçam no futuro alguns estudos complementares. A forma de medir a produtividade 
(artigos em relação ao número de coautores) talvez superestime o papel de pequenos laboratórios de departamentos de universidades e igualmente subestime o papel dos grandes laboratórios, em que a produção científica é, por vezes, de autoria de muitos pesquisadores. De outro lado, fica evidente que a forma de organizar os dados do levantamento, similar a uma abordagem de "grupos de pesquisa", talvez condicione estas conclusões, tema que voltaremos nas conclusões finais desta resenha.

O capítulo 11, produzido por Pedro Miranda e Graziela Zucoloto, avalia o grau do conhecimento dito "inovador", mensurado a partir de estatísticas de patentes, nas infraestruturas de pesquisa que fazem parte do levantamento de campo. Foram identificados 764 inventores, segundo registro de patentes do Inpi, atuando em 548 das 1.760 infraestruturas avaliadas, em 52 instituições. Como sintetiza a introdução do livro: os autores mostram que esse conhecimento inovador, está "relativamente mais concentrado em infraestruturas com capacidade técnica considerada avançada em relação aos padrões brasileiros, localizadas na região Sudeste e que iniciaram suas operações nas décadas de 1970, 1980 e 1990”. Aqui, as patentes são consideradas uma boa proxy do conhecimento tido como "inovador". Uma das conclusões é de que o número médio de patentes por infraestrutura apresentado pelas infraestruturas mais antigas chega a ser mais do que o dobro daquele registrado pelas instituições mais recentes. Há também uma forte correlação ente a prestação de serviço, sobretudo a empresas, e a atividade de patenteamento, bem como sobressaem os laboratórios das áreas de engenharia. Um ponto que pode sugerir linhas de pesquisa complementares a este levantamento é questionar a efetividade dos depósitos de patentes, em termos da transferência de tecnologia. Levantamentos recentes têm mostrado que as universidades brasileiras aumentaram muito o registro de propriedade intelectual, mas pouco se sabe se este movimento faz sentido em termos econômico, ou seja, se estes depósitos chegam a ser comercializados.

No capítulo 12, Luís Fernando Tironi aborda o tema dos serviços tecnológicos, destacando cinco deles - metrologia, calibração, ensaios e testes, certificação e acreditação -, que constituem o núcleo do que é conhecido como Tecnologia Industrial Básica (TIB). O texto introduz a questão com uma breve descrição do Sistema Nacional de Metrologia, Normalização e Qualidade Industrial e do Sistema Brasileiro de Avaliação de Conformidade, e mostra que a importância das TIB reside no crescente uso de barreiras técnicas e sanitárias para acesso aos diversos mercados. A análise do levantamento de campo levou em conta três recortes, além do universo da pesquisa: infraestruturas que prestam serviços técnico-científicos; o subconjunto que presta (pelo menos um) serviços de metrologia, calibração, inspeção e certifica- 
ção; e o subconjunto detentor de acreditação. A partir deste recorte, examinou-se sua propensão para desenvolver trabalhos em articulação com empresas. Das 1.760 infraestruturas de pesquisa, 1.208 informaram que prestam serviço técnico-científico, 195 afirmaram prestar serviços de metrologia, calibração, inspeção e certificação e 48 eram acreditadas. Como seria de se esperar, estes dois últimos grupos atuam principalmente atendendo à indústria de transformação, e suas fontes de financiamento são principalmente a Finep, a prestação de serviços e a Petrobras. Ou seja, são laboratórios que atuam como interfaces entre as instituições de ensino, pesquisa e desenvolvimento científico e tecnológico às quais pertencem e os setores produtivos.

De autoria de Gilson Geraldino, o capítulo 13 tem dois objetivos: analisar com dados da Pintec se o uso de infraestrutura impacta na decisão das empresas de fazer P\&D e de inovar; e verificar qual o impacto da cooperação servindo-se dos dados da pesquisa do Ipea-CNPq-Finep. O autor salienta a relevância da cooperação nos estudos sobre Sistemas Nacionais de Inovação, mas mostra que a literatura sobre a cooperação não é conclusiva. A partir dos dados da Pintec, verifica-se que a cooperação direta ou indireta no uso de infraestrutura é efetivamente relevante para P\&D externa e contínua, a interação com instituições estrangeiras é baixa e as universidades são instituições importantes nesta cooperação. Em termos de informações para inovar, a Pintec também revela que universidades e institutos de pesquisa estão entre as instituiçõos mais importantes, sendo que os objetos de cooperação mais significativos são P\&D e ensaios para testes. Os dados do survey, por sua vez, revelam que: os laboratórios da amostra são utilizados sistemática e continuamente, porém com utilização contínua para um fim específico não tão elevada; equipar os laboratórios é em geral relativamente barato, mas mantê-los é em geral relativamente caro; e a cooperação dos laboratórios com as empresas do Brasil é o dobro daquela com as empresas do exterior. Além disso, os dados ainda sugerem: que a atividade laboratorial contínua relevante para fins de cooperação com empresas é a pesquisa; que a prestação de serviços (técnico-científicos ou tecnológicos) e a pesquisa estão associadas a laboratórios acreditados; e que os custos de equipar ou manter, via de regra, não afetam a probabilidade de utilização da infraestrutura laboratorial. Este conjunto de evidências indica que o uso focado de infraestrutura laboratorial e a cooperação com empresas estão significativamente associados. Os resultados encontrados variam de setor para setor, sendo curiosamente maiores em setores mais tradicionais.

O capítulo 14, elaborado por Marcos Arcuri, enfoca as políticas de investimento em infraestrutura de pesquisa, a partir da identificação das prioridades nacionais, da comparação do Brasil com outros países e das informaçôes da pesquisa de campo. $\mathrm{O}$ 
objetivo é saber se o financiamento dá suporte ao desenvolvimento da infraestrutura de C\&T. O texto sumariza os principais documentos de política de C\&T (A Estratégia Nacional - ENCTI e o Livro Azul, da IV Conferência Nacional) e apresenta suas linhas de ação, sem questionar se de fato eles sintetizam uma estratégia, ou se são a soma de muitos desejos. O autor indica a importância das universidades para a infraestrutura laboratorial do país, mas dá grande ênfase aos institutos do atual MCTIC, por supostamente estarem voltados para temas de interesse estratégico, sem atentar que alguns dos efetivos laboratórios nacionais não estão no MCTI, como a Embrapa e a Fiocruz. O artigo afirma que o governo, além de seguir as prioridades de seus planos, orienta seus gastos de acordo com as necessidades de crescimento econômico, mas mostra que o principal gasto com infraestrutura é o dispêndio nas instituições de ensino superior. $\mathrm{Na}$ sequência, são abordados os instrumentos de financiamento, especialmente os Fundos Setoriais, uma tentativa de solucionar a instabilidade crônica da alocação e recursos, bem como para superar visões lineares da C\&TI, o que infelizmente hoje se revela problemático. Os dados da pesquisa permitem fazer uma radiografia das principais fontes de financiamento: Petrobras, CNPq (provavelmente com recursos do FNDCT), Finep e as Fundações Estaduais de Amparo (que mereceriam maior detalhe), mas revelam também seu baixo valor médio, em instalações de porte pequeno e com número reduzido de doutores, o que de certo modo mostra o predomínio de uma abordagem ofertista, ainda distante de uma verdadeira estratégia nacional de CT\&I.

Por fim, o capítulo 15, de autoria de Paulo Meyer do Nascimento, analisa as áreas científicas nas quais o Brasil é mais competitivo internacionalmente, e mostra quais as instituições de destaque em cada uma dessas áreas. $\mathrm{O}$ artigo inicia com uma avaliação do crescimento do número de artigos publicados em periódicos indexados, mas salienta que os indicadores de impacto sugerem que os artigos assinados por autores sediados no país ainda têm reduzida visibilidade internacional e que, a partir do fim da década de 2000, haveria certo esgotamento do potencial de expansão da produção científica brasileira. As hipóteses são que a base científica brasileira tenha alcançando uma certa estabilidade em termos de participação na produção mundial de artigos científicos e que seu crescimento quantitativo não foi acompanhado por igual aumento de seus impactos, medidos pelos índices de citações das revistas em que estes artigos são publicados. Talvez, em outra ocasião, esta análise possa ser complementada pela avaliação de como a ampliação da base de periódicos com publicações brasileiras afetou este desempenho, bem como por indicadores de impacto não das revistas, mas sim das citações dos próprios artigos, que parecem 
indicar que a qualidade (medida pelas citaçôes) tem crescido menos do que a média mundial, ficando abaixo inclusive de alguns países latino-americanos. Na sequência, o autor avalia o grau de especialização desta produção científica por meio de uma medida de vantagem comparativa revelada. Os dados mostram uma especialização nas áreas de ciências da vida e biomedicina, com destaque para medicina tropical, parasitologia, odontologia, cirurgia e saúde oral e agricultura, além da microscopia, que, a despeito de figurar como de alto nível de especialização relativa no Brasil, mostra-se distante da fronteira no quesito impacto (uma hipótese é que isso talvez reflita mais as políticas de fomento e a demanda dispersa por equipamentos). Esta avaliação é refinada com indicadores adicionais, que mostram que, nestas áreas, o país concentra elevada parcela da produção mundial e possui instituições nacionais entre as cinco que mais publicam.

$\mathrm{O}$ conjunto destes artigos forma uma impressionante radiografia da infraestrutura de pesquisa do Brasil. A iniciativa do Ipea-CNPq-Finep merece assim um efusivo reconhecimento. Por esta razão, vale a pena voltar ao artigo de Fernanda De Negri e Flávia Squeff, que abre esta coletânea, pois as organizadoras sintetizam muito bem os principais achados da pesquisa. Ao lado de mostrar que há um razoável - dado o fato de os laboratórios estarem mais voltados para pesquisa e ensino - compartilhamento desta infraestrutura com empresas, notadamente prestação de serviço, ainda que de forma esporádica, as autoras vão ao cerne do diagnóstico que é a dispersão de esforços de financiamento da infraestrutura de pesquisa:

O número total de pesquisadores distintos atuando nessas 1.760 infraestruturas é de 7.090, o que já evidencia uma das características mais contundentes da infraestrutura de pesquisa no Brasil: o tamanho limitado dos laboratórios. Em média, cada laboratório abriga apenas cerca de quatro pesquisadores [...]

[...] [todos os dados levantados] apontam, inequivocamente, para a mesma direção: fica claro que o país dispõe de pouquissimas instalaçôes de pesquisa de grande porte. Apenas pouco mais de vinte infraestruturas entre as 1.760 pesquisadas declararam que o valor total das suas instalaçôes físicas e de seus equipamentos de pesquisa supera $R \$ 20$ milhöes [...]

O que esse levantamento mostrou é que a imensa maioria da nossa infraestrutura de pesquisa é formada de pequenos laboratórios espalhados nas universidades brasileiras. São infraestruturas nas quais trabalham, em média, apenas quatro pesquisadores e cujos equipamentos de pesquisa, em cerca de 90\% dos casos, custam menos de R\$ 2 milhões. Neste levantamento existem apenas dez infraestruturas com valor superior 
a $R \$ 30$ milhöes, somados os equipamentos e as instalações físicas. A comparação das infraestruturas nacionais com exemplos internacionais, seja na Europa, seja nos Estados Unidos, evidencia essa limitação". ${ }^{2}$

Estas conclusões são extremamente importantes, em termos do realinhamento das políticas nacionais de CT\&I. Elas tocam num tema que tem sido objeto de outros trabalhos interessantes do Ipea: o papel dos laboratórios nacionais e de alguns institutos de pesquisa com enfoque setoriais enquanto instituiçôes voltadas para missões, diferentemente das universidades, cujo papel central é formar recursos humanos, ainda que desempenhem uma função muito relevante na pesquisa e na cooperação com o setor privado.

Nesse sentido, talvez fosse o caso de estimular as autoras a fazerem um complemento desta coletânea, a partir de um enfoque distinto: examinar a infraestrutura instalada segundo as principais instituições - Embrapa, Fiocruz, Butantã, CPqD, CNPEM, IPT, CTA, Inpe, etc. -, vis-à-vis as universidades, especialmente as de pesquisa. A organização dos dados por laboratório - quase que por "grupos de pesquisa", como já salientado nesta resenha - é muito útil, mas talvez seja mais aderente às universidades, em que a lógica da pesquisa e as culturas "departamentais" fragmentam, não obrigatoriamente em termos negativos, esta infraestrutura. Isso também acontece nos grandes laboratórios, nesse caso nem sempre de forma positiva. Mas tal abordagem complementar permitiria avançar na direção de uma política nacional menos ofertista e mais voltada para os desafios nacionais. Há muito está claro que um dos maiores problemas de nosso sistema de inovação é a baixíssima, senão nula, capacidade dos entes nacionais responsáveis pela política de estabelecer estratégias, dignas deste nome, de definir missões de suas unidades de pesquisa e de contratá-las para cumprir estas missões. Não é surpreendente que muitos dos chamados laboratórios nacionais da União não estejam vinculados ao MCTIC e que, em paralelo, muitas de suas unidades de pesquisa assemelhem-se às universidades. Há, contudo, que ter cautela nessa direção: o déficit de capacitação para definir prioridades é tão grande, que muitas vezes é mais recomendável fazer apoio a projetos em chamadas competitivas do que fazer escolhas, que sejam de fato boas escolhas.

Como já mencionado anteriormente, sempre se podem fazer observaçōes pontuais acerca de um ou outro artigo. Mas deve-se, especialmente, reconhecer o grande mérito desta pesquisa e de seus 15 artigos. Aqui, o que conta é o conjunto da obra, nesse caso específico, amplamente positivo e estimulante.

2 DE NEGRI, Fernanda; SQUEFF, Flávia de Holanda Schmidt. O mapeamento da infraestrutura científica e tecnológica do Brasil. In: DE NEGRI, F.; SQUEFF, F. H. S. (Org.). Sistemas setoriais de inovação e infraestrutura de pesquisa no Brasil. Brasília: Ipea/ Finep/CNPq, 2016. 

A Revista Brasileira de Inovação está aberta à comunidade científica para divulgação de artigos originais e inéditos, de natureza teórica ou aplicada, resultados de pesquisas, bem como trabalhos que contribuam para o resgate da história das instituições brasileiras no campo da ciência, da tecnologia e da inovação.

São aceitas submissões de artigos com no máximo 8.000 palavras e resenhas de até 1.000 palavras, inéditos em português, inglês ou espanhol.

Todos os trabalhos devem ser submetidos via Sistema Eletrônico de Editoração de Revistas (SEER) e se enquadrar na linha editorial da revista, observando as normas e orientações indicadas a seguir:

- os trabalhos devem ser redigidos conforme a norma de apresentação de artigos da Associação Brasileira de Normas Técnicas - ABNT (NBR6022) ou norma ISO equivalente, digitados no editor de texto Word 6.0 (extensão doc. ou docx.), texto na fonte Times New Roman 12; configuração de página A4; margens direita, superior e inferior com 2,5cm; margem esquerda com 3cm; espaçamento entrelinhas de 1,5; recuo de 1,25 na primeira linha; alinhamento do texto justificado; e numeração de páginas no canto superior direito;

- $\quad$ os artigos devem ser submetidos contendo resumo, título e palavras-chave em seu idioma original e em inglês e classificação segundo o Classification System for Journal Articles do Journal Economic Literature. O resumo/abstract deve ter no máximo 150 palavras e possuir de três a cinco palavras-chave;

- as resenhas devem versar sobre livros publicados nos últimos três anos, relacionados à inovação e que estejam alinhados ao escopo editorial da revista;

- as obras citadas no corpo do texto e em notas de rodapé (autor, ano da publicação e, quando for o caso, página) deverão estar completas nas referências bibliográficas ao final do texto.

Os artigos são avaliados no sistema blind review por três pareceristas de instituições distintas daquela à qual o(s) autor(es) está(ão) vinculado(s) e as resenhas são avaliadas pelos editores da revista.

Os direitos autorais dos trabalhos aprovados são automaticamente transferidos à $R B I$ como condição para sua publicação, podendo ser compartilhados desde que com o reconhecimento de sua autoria e publicação inicial nesta revista.

Mais informações: <http://www.ige.unicamp.br/ojs/rbi/> 
